\title{
Determination of the relationship between soil properties and earthquake damage with the aid of neural networks: a case study in Adapazarı, Turkey
}

\author{
E. Bol \\ Civil Engineering Department, Engineering Faculty, Sakarya University, Sakarya, Turkey \\ Correspondence to: E. Bol (ebol@sakarya.edu.tr)
}

Received: 28 June 2012 - Accepted: 29 August 2012 - Published: 25 September 2012

\begin{abstract}
The building stock in the city of Adapazar1, Turkey, experienced widespread damage during the 1999 Marmara earthquake. An attempt was made to relate structural damage to the type of subsoil in this study. The Adapazarı soil database has been established which contains information on boreholes, cone penetration and laboratory testing since 1996 and is being updated continuously. The database has been organised using a geographical information system software. Several numeric soil profiles across the city were then taken to establish a back propagation neural network model to enable the investigator to estimate probable structural damage by referring to the type of soils at the usual footing embedment depths. Ten cross sections comprising 140 data each were used to form scanlines of $1400 \mathrm{~m}$ length. The input for the neural networks were the physical, mechanical and dynamic properties of soils while the resulting damage ratio data formed the target layer. Feedforward, backward spreading networks were employed in modelling. Numeric data for eight cross sections were employed for the learning process, whereas data for two cross sections were used to test the model. The proposed model was found to predict the damage ratios successfully. The general evaluation of the city following the earthquake has shown that the structural damage was minimal in a limited section of the city where the bedrock outcrops. The damage in the flat areas around the outcropping rock covered by lacustrine clays of high and intermediate plasticity was markedly low. However, damage and destruction was obvious in the central parts of the city where liquefaction and cyclic softening cases were abundant.
\end{abstract}

\section{Introduction}

The issue of the effect of local soil conditions and the behaviour of structures during earthquakes has been investigated for a considerable time. MacMurdo (1824) has, as early as 1824, claimed that during the 1819 Kachchh, India (formerly known as Cutch or Kutch) earthquake “... that buildings situated upon rock were not by any means so much affected by the earthquake as those whose foundations did not reach to the bottom of the soil...". Kramer (1996) has made a detailed review of the research conducted on the influence of local soil conditions on earthquake damage. It is seen that soil conditions affect the amplitude, frequency and duration of the ground movements. The extent of their influence depends on the geometry of the subsurface, surface topography and the properties of the input motion. Alluvial valleys confine the body waves $(P$ and $S$ ) and cause excessive Rayleigh and Love surface waves.

Previous research on the effect of soil properties on the distribution of damage in Adapazarı has indicated that, unlike those founded on shallow, stiff residual profiles on bedrock in the southern parts of the city, three to four storey buildings on the stiff soils of the plain suffered significantly more damage possibly due to ground amplification (Bakır et al., 2002, 2005). It is claimed that, in contrast, the soft soils of the plain have formed a kind of base insulation. Consequently, the buildings founded on such soils have suffered less structural damage while cases of tilting, excessive settlement and bearing capacity failure were frequent. Trifunac and Todorovska (1998) have also claimed that soft soils in vicinity of the earthquake zone act as passive insulators.

In Adapazar1, 5078 buildings corresponding to $27 \%$ of the building stock collapsed or were damaged beyond use during 
the 1999 earthquake (Sancio et al., 2002). Damage rose to $50 \%$ in the districts where the depths of the Holocene and recent sediments were as high as $1000 \mathrm{~m}$ (Komazawa et al., 2002), whereas virtually no damage was observed in the districts where the bedrock outcrops (Bakır et al., 2005). Strongmotion records from aftershocks at different sites in the city indicate that the alluvial basin amplified the ground motion significantly (Trifunac and Todorovska, 1998).

It is essential to expose three main components involved, in order to explain the causes of the damage. These are the properties of the strong motion, the structural and geometric features of the structures, and the properties of the ground. The 17 August 1999 earthquake shook the region for $48 \mathrm{~s}$, and the moment magnitude was measured at $M_{\mathrm{W}}=7.4$. The torn segment of the North Anatolian Fault, which is a right lateral strike-slip fault, consists of four segments with a total length of $126 \mathrm{~km}$ (Lettis et al., 2002). Adapazarı is about 8 to $10 \mathrm{~km}$ to the north of this torn segment. The structural and geometric features of the buildings, which are probably major contributors to damage and collapse, could only be partially included in this study. The reason for this is that such a study should have been carried out immediately after the earthquake, before the debris was removed. In addition, some researchers of the incident are of the opinion that the quality of the superstructures was not the prime factor in determining the extent of damage and collapses: “...Our preliminary interpretation of the field data suggests that the type and width of structures do not significantly influence the degree of ground failure..." (Sancio et al., 2002).

İnce (2011) researched the Old Istanbul (Turkey) city by using microzonation maps which are generated via geographical information system (GIS). Research has found that causes of the damage of the 1894 Istanbul earthquake to historical artefacts and structures were soil amplification and partial liquefaction.

Despite those claims, one can make a diagnosis of the damage: the distribution of the damage appears to have been concentrated in two regions of Adapazarı regardless of the type of the buildings. The Group A buildings comprise mostly residences, which are more homogeneous in terms of size and height. The second zone B consisted of taller edifices such as government offices and trade centers.

One might initially be inclined to think that this paper places heavier emphasis on the properties of soils in comparison to the structural properties of the buildings. Although this is obvious from the ensuing discussion, it has to be remembered that the quality of the buildings in the areas studied shows significant differences because they have been designed with three different building codes during the past $40 \mathrm{yr}$ and assessing their quality would have been practically impossible. This is why the author had to make a general assessment of the damage. This distinction of the zones was taken into consideration when selecting profiles to be used for neural network (NN) applications. An attempt was then made to merge the results (simulation) of the different axes

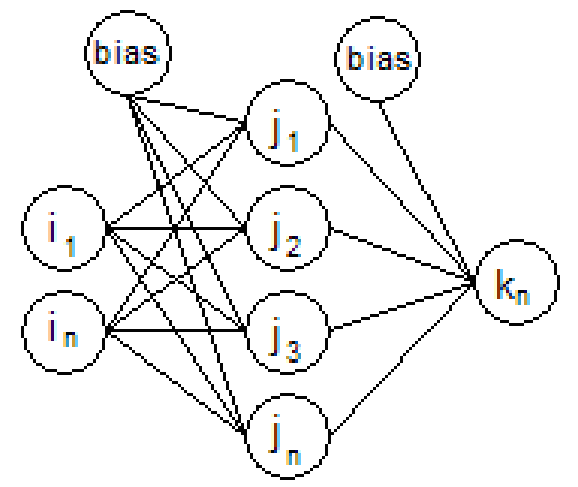

Fig. 1. Structure of a fully interconnected feedforward multi-layer perceptron.

in order to see whether a generalization for the whole of the city was possible. In addition, the NN model trained for the cross sections from the northern part of the city was applied to the southern part for the same purpose.

\section{Neural networks (NN)}

Soft computing methods such as fuzzy logic, neural network, probabilistic reasoning and genetic algorithms have found wide application in engineering research recently. This investigation has employed the concept of neural networks developed in the 1940s, in providing explanations to earthquake damage.

Neural network $(\mathrm{NN})$ analysis is a logical approach that simulates the functions of the human brain using basic computation methods. Imitating the basic functions of the brain such as learning, decision making, and adapting to new situations is one of its basic features. Simulated brain cells form a network of cells consisting of neurons that are interconnected in various ways. NN architectures have generally three or more layers, which include an input layer, an output layer and one or more hidden layers in which neurons are linked to each other with changeable weighted interconnections. Feedforward neural network comprises three layers: $i, j, k$ corresponding to input, hidden and output. It is possible to increase the number of layers depending on the number of hidden layers. In addition a bias exists that depends on the hidden input and output layers (Fig. 1). Each layer is formed by neurons, the number of which is under the control of the modeller, and the layers in question are interconnected by modifiable weights. But connection among the neurons within a specific layer is not allowed. Initially, the values of randomly appointed connection forces are varied until training is successfully completed by the use of a training algorithm. It then obtains the existing knowledge for the examples used in the process of training and stores them after each iteration. In a new input group, the output group is consequently obtained by the help of a feedforward $\mathrm{NN}$ with the 
information acquired and retained connection weights. This type of NN structure is called fully interconnected feedforward multi-layer perceptron (MLP) and is widely employed in practice. The back-propagation (BP) algorithm is the most widely used training algorithm for multi-layered feedforward networks. The BP algorithm takes place in two stages. The first one is the forward phase and second one is the backward phase. The activations are propagated from the input to the output layer in the forward phase. Then the error between the observed actual value and the desired value in the output layer is propagated backwards in order to modify the weights and the bias values in the backward phase. The training of the network is carried out through a large number of training sets and training cycles, and it is achieved by adjusting the weights. Finding the optimal set of weights is the aim of the training procedure. The weighted sum of input components is calculated in the forward phase as

net $_{j}=\sum_{i=1}^{n} w_{i j} x_{i}+$ bias $_{j}$

where net ${ }_{j}$ is the weighted sum of the $j$-th neuron for the input received from the preceding layer with $n$ neurons, $w_{i j}$ the weight between the $j$-th neuron and the $i$-th neuron in the preceding layer, and $x_{i}$ the output of the $i$-th neuron in the preceding layer.

out ${ }_{j}$ is the output of the $j$-th neuron and it is evaluated with a sigmoid function:

out $_{j}=f\left(\right.$ net $\left._{j}\right)=\frac{1}{1+e^{-\left(\text {net }_{j}\right)}}$.

Because gradient descent and gradient descent with momentum, which are back propagation training algorithms, are slow, several adaptive training algorithms for $\mathrm{NN}$ have recently been developed. These are conjugate gradient algorithm (CG) and scaled conjugate gradient algorithm (SCG) which was used in this study as the optimization algorithm, which is all set to standard values suggested in Moller (1993). The output of the net is compared to the value produced by the net to determine the error which is used to evaluate the performance of the net. The performance function of the feedforward nets can be used as the performance function which is the sum of squared errors - SSE. Feedforward-back spreading process is carried on until the sum of squared errors is reached. The sum of squared errors (SSE) is determined by the equation

$\mathrm{SSE}=\sum_{i=1}^{N}\left(T_{i}-\text { out }_{i}\right)^{2}$.

$T_{i}$ and out ${ }_{i}$ are the target output and neural network output, respectively, and $N$ is the number of neurons in the output layer.

\section{The Adapazarı geotechnical database}

The database used for this study has been selectively established over the years. The test results performed only by the Universities of Sakarya (Turkey), California (Berkeley), and Istanbul Kültür were found to be credible. All other data available to the public however have been found to be of questionable quality, hence excluded.

A detailed study of the soils was performed through 818 boreholes and 306 cone penetration tests to collect the physical and mechanical properties in the Adapazarı database. The information so collected was then used as input for the neural network model.

The usual depth of the boreholes was $15 \mathrm{~m}$, with the SPT performed each $1.5 \mathrm{~m}$ taking disturbed and undisturbed samples. In contrast, the cone penetration test provided data for every $2 \mathrm{~cm}$ and formed a voluminous source of almost all properties for the subsoil. Accompanying research programs have in addition, supplied data pertaining to the dissipation of excess pore water pressures during cone penetration, hence coefficients of hydraulic conductivity. Table 1 summarizes the number of data in the Adapazarı database. The database comprises results of soil classification by TS1500 (2000), liquid limit $\left(w_{\mathrm{L}}\right)$, plastic limit $\left(w_{\mathrm{P}}\right)$, natural water content $\left(w_{\mathrm{n}}\right)$, average grain size $\left(D_{50}\right)$ as well as standard penetration resistances (SPT-N), undrained strength $\left(c_{\mathrm{u}}\right)$, cone tip resistances $\left(q_{\mathrm{c}}\right)$, side friction $\left(f_{\mathrm{s}}\right)$ and excess pore water pressures $\left(u_{2}\right)$ during penetration.

\section{Thematic maps}

The data on the selected profiles of the city studied were digitized to help establish the thematic maps. Each profile of the city consists of up to 100 building "plots". The borders of each section were hidden after digitization with the city limits left open. Figure 2 depicts the area studied with thick borders. Stars indicate boreholes here and the circles the cone penetration sites. The number of investigations appears to be satisfactory for the area studied. Figure 2 also shows the profiles where input and output parameters for the NN study were applied. Measurements of plasticity index $\left(I_{\mathrm{P}}\right)$, liquidity index $\left(I_{\mathrm{L}}\right)$, average grain size $\left(D_{50}\right)$, fines content (FC), cone tip resistance $\left(q_{\mathrm{c}}\right)$, and liquefaction potential index (LPI) were made to classify the soils by TS1500/2000, in order to relate the type of soil to the damage maps, providing the damage ratios (DR) in the city for different depths. 
Table 1. Features of the Adapazarı geotechnical database (number of data available).

\begin{tabular}{lllllllllllllll}
\hline CPTUs & Borings & SPTN & $w_{\mathrm{L}}$ & $I_{\mathrm{P}}$ & $w_{\mathrm{n}}$ & $\%$ FC & $\%$ Clay & Class & $e_{0}$ & $\begin{array}{l}\rho_{\mathrm{n}} \\
\left(\mathrm{kN} \mathrm{m}^{-3}\right)\end{array}$ & $\begin{array}{l}c_{\mathrm{u}} \\
(\mathrm{kPa})\end{array}$ & $\begin{array}{c}\text { Consolidation } \\
\text { Vs }\end{array}$ & $\begin{array}{l}\text { Dissipation } \\
\text { Tests }\end{array}$ \\
\hline 306 & 818 & 6563 & 6085 & 6085 & 6085 & 6085 & 1561 & 6085 & 760 & 818 & 853 & 240 & 235 & 226 \\
\hline
\end{tabular}

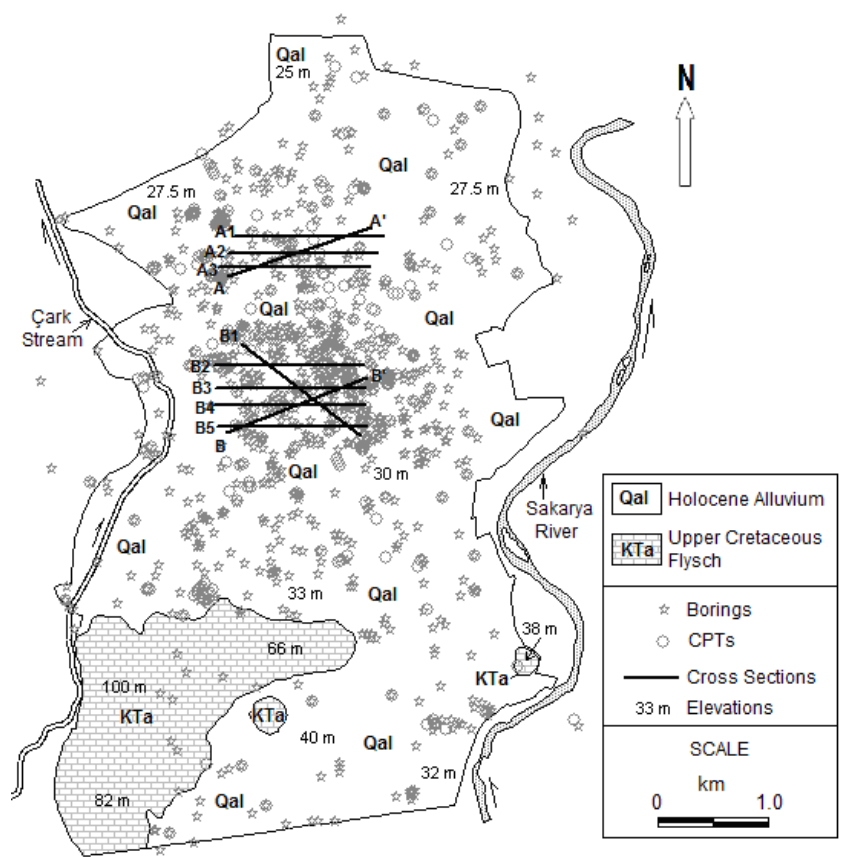

Fig. 2. The area of study in Adapazarı and the points of drilling and sounding.

\subsection{Damage map for the 1999 earthquake}

The conditions of the building stock in the city of Adapazarı were evaluated by examining the structural damage observed and were recorded by the ministry officials after the earthquake. The classification was implemented in four categories: heavily damaged/collapsed, medium damage, lightly damaged and sound. The medium damage category was the controversial item because it was defined as a "building that will function after retrofitting".

This official classification was nevertheless taken as reference to form a damage map that would be used to provide explanation of the cause of the damage and collapse. A comparison of the damage map was performed against maps of cone tip resistance $\left(q_{\mathrm{c}}\right)$ and several physical properties. The damage was assessed on basis of "relative damage ratio" that normalizes the damage by the ratio of damaged buildings over their total number, because the density of buildings was highly variable in different districts of the city. This however resulted in errors in districts with large surface areas, because a constant relative damage ratio was adopted for each district. This prevented the investigator to make a distinction of the extent of damage within each district. To avoid this error, the 1/1000 settlement maps of the administrative districts of central Adapazarı and the neighbouring district of Erenler were divided into $0.25 \mathrm{~km}$ square $\left(0.0625 \mathrm{~km}^{2}\right)$ grids where the total number of buildings and the heavily damaged/collapsed ones were counted to reach correct relative damage ratios within each square. Thus, the output parameter Damage ratio $(D R)$ is defined as

$\mathrm{DR}=\frac{\text { Heavily Damaged or Collapsed Buildings }}{\text { Total Number of Buildings }}$.

It was found that the damage was markedly heavy along the baselines through the city centre and the northern part of the city, whereas relatively light damage appeared along an east-west axis (Fig. 3a). No tally of damage was taken in zones where the bedrock surfaced, as sporadic damage observed here was attributed solely to low quality construction, and not the property of the subgrade.

Use of aerial photos taken soon after the earthquake was also made in order to understand the relationship of damage and local soil conditions (Fig. 4a). It is noteworthy that damage was concentrated in the SE-NW extending boulevard separating the sub-districts of Tigcilar (TI) and Semerciler (SM), and structural collapses here were mostly in the form of pancaking. The military draft office and the courthouse, whose sizes were notably larger than the typical building size in Adapazarı, also collapsed by pancaking. The governor's office, which had been retrofitted after the 1967 Mudurnu earthquake $\left(M_{\mathrm{w}}=6.8, t=34 \mathrm{~s}\right)$, did not collapse, but the damage was so extensive that it had to be torn down. Damages in the sub-districts of Tigcilar and Yenigun were observed to be due to toppling, excessive settlement and tilting of the buildings.

It can be seen upon inspection of the liquefaction and cone tip resistance maps (Fig. $3 b$ and d) for this separating line that the $q_{\mathrm{c}}$ values in the western part of Semerciler district are higher than the values measured in the east (Tigcilar), but that they tended to drop towards the east where the liquefaction potential indices (LPI) increased to liquefaction levels. The relative damage ratios in this part of the city were determined to be around 30 to $35 \%$, suggesting the possibility that damage in Tigcilar emanated from inferior soil conditions thus excessive settlements and tilting, whereas damage was seen to be of structural collapse type in the districts where soil conditions were slightly better than Tigcilar. This suggests the possibility that poor soils may have acted as a base insulator, preventing violent structural failure such as pancaking thus reducing fatalities. In the end nevertheless, most 

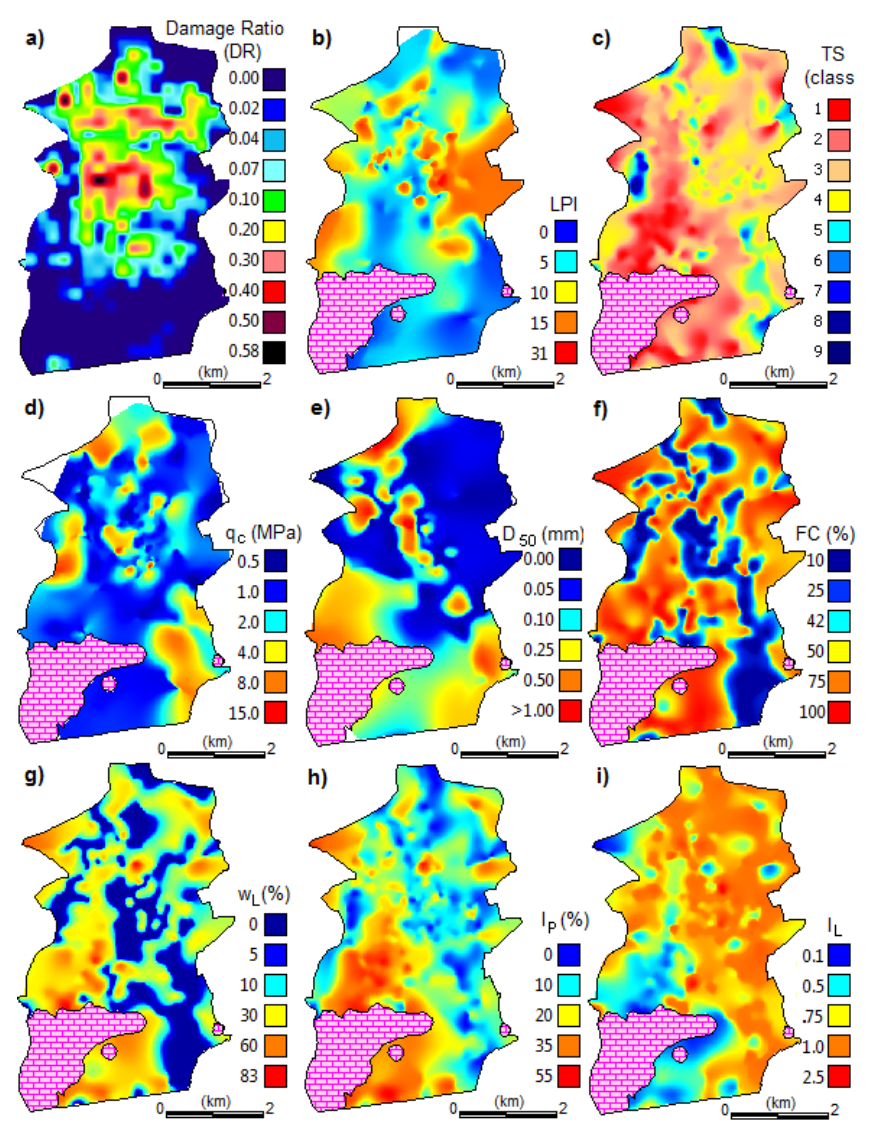

Fig. 3. Thematic maps used for establishing the NN model.

of the buildings had became defunct due to the earthquake, whether they collapsed or deformed excessively, merely becoming uninhabitable.

\subsection{The liquefaction potential index (LPI) map}

It is now an established fact that a significant part of the damage has been caused by the failure of sandy silts and silts during the 1999 earthquake (Bray et al., 2004a, b; Bol et al., 2005, 2008). It was therefore inevitable that liquefaction potential is included as an input parameter in modelling the damage-soil properties with the NN. The concept of liquefaction potential index (LPI) appeared to be a suitable choice for the purpose. All the soil profiles obtained by the cone penetration tests have thus been employed to obtain the LPI values. The LPI can be evaluated by the following expression (Iwasaki et al., 1978):

$\mathrm{LPI}=\int_{0}^{20 \mathrm{~m}} F w(z) \mathrm{d} z$

where

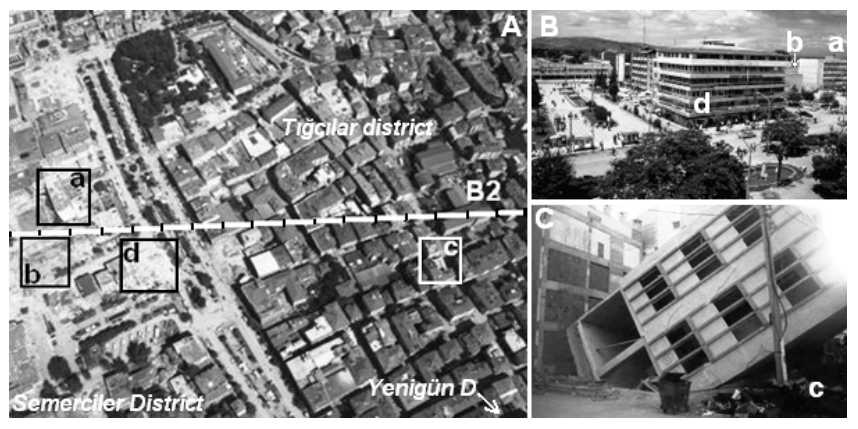

Fig. 4. (A) Aerial view of central Adapazarı and the location of cross section of B2 line. (B) Governor's office Adapazarı before earthquake (a), military drafting office and court house (b) and ATSO building (d). (C) building toppled as a result of liquefaction in Tigcilar district (c).

$\mathrm{FS} \leq 1 \Rightarrow F=1-\mathrm{FS}$

$\mathrm{FS}>0 \Rightarrow F=0$

$w(z)=10-0.5 z$

and $z$ is the depth and $w(z)$ the depth weighting factor. The cyclic stress ratio approach proposed by Robertson and Wride (1998) was used to determine the liquefiable layers and calculate the factor of safety (FS).

The soil behaviour type index, $I_{\mathrm{c}}$ given in Eq. (6), indicates that values higher than 2.6 that comprise clayey silt, silty clay, and clays are not liquefaction prone due to their high clay contents. $Q$ and $F$ represent the normalized values of tip resistance and side adhesion/friction of the cone, respectively.

$I_{\mathrm{c}}=\left[(3.47-\log Q)^{2}+(\log F+1.22)^{2}\right]^{0.5}$.

The factor of safety for the non-liquefiable layers was assumed as zero ( $\mathrm{FS}=0)$, and the LPI would then take values of zero as well. In cases where the factor of safety was lower than unity, 100 was appointed to LPI within the top $20 \mathrm{~m}$ of the soil profile. The liquefaction severity can then be described by the limits in Table 2 .

As it was found that non-plastic silts were concentrated in the top $10 \mathrm{~m}$ of the profiles and the CPT testing was performed at the top $15 \mathrm{~m}$, the LPI performance was evaluated for these depths (Önalp et al., 2001). This means that soundings would be shallower than the $20 \mathrm{~m}$ stipulated in the LPI approach, and such evaluation would involve a certain amount of error in diagnosing the risk of liquefaction with reference to the original proposal. In such a situation a thematic map comprising four regions (negligible to none, minor, moderate, major damage) that are separated from each other with definite borders will inevitably contain errors. Because it is necessary to adapt the LPI scales (shown in Table 2) for $10 \mathrm{~m}$ depths, it will be necessary now to investigate how much these borders will be displaced by using 
Table 2. Liquefaction severity as a function of liquefaction potential index, LPI (Iwasaki et al., 1978).

\begin{tabular}{ll}
\hline Liquefaction severity & LPI \\
\hline Little to none & LPI $=0$ \\
Minor & $0<\mathrm{LPI}<5$ \\
Moderate & $5<$ LPI $<15$ \\
Major & $15<$ LPI \\
\hline
\end{tabular}

$10 \mathrm{~m}$ depths for evaluation, instead of the usual $20 \mathrm{~m}$. The thematic map has consequently been established not by these borderline values but by the numerical values they assume directly (Fig. 3b) to evade the problems that arise by using shallower depths. The values indicated in the legend of Fig. 3 that are formed in the geographical information system (GIS) medium are thus illustrated by their direct numerical values rather than attempting to identify them by using gradual changes in colours. The NN accordingly does not compare borderline values but evaluates whether the LPI values in a certain section are higher and lower than its neighbours when evaluating the influence of LPI on damage. Nonetheless, the fact that the LPI values calculated by formulae (5) are higher than $15 \mathrm{~m}$ for the top $10 \mathrm{~m}$ is an excellent indicator of the extent of liquefaction, such as the orange and red coloured zones depicted in Fig. 3b. The districts of Tigcilar and Yenigun shown in the map (Fig. 3b) were the most vulnerable from the point of view of liquefaction as witnessed after the earthquake and were given priority in this study. The adverse effects of relatively widespread liquefaction and ground failure in the eastern districts of the city are unfortunately not fully reflected in the results, due to relatively small number of buildings here and can be quoted as a shortcoming of this approach.

\subsection{The soil maps}

The results of classification carried out on laboratory findings and cone penetration were transferred to the geographical information system (GIS). The GIS software such as MapInfo requires that the symbols appointed to soils identified $(\mathrm{CH}$, CI, CL, MH, MI, ML, SW, SP-SM ...) have a corresponding digit in order to perform interpolation. The soil classes were accordingly appointed digits ranging from 1 to 9 to meet this requirement. This is due to the fact that the software selects two points and performs interpolation to evaluate values in the empty regions between them. Accordingly, data were stored in an area labelled as Soil Category in the database. The finest and the most plastic soils $(\mathrm{CH})$ and the seldom encountered $\mathrm{MH}$ took the digit 1 , whereas the nonplastics and gravels $\left(D_{50}>2 \mathrm{~mm}\right)$ assumed the digit 9 . Other digits are listed in Table 3 . The reason why clayey sands do not appear in the table is because almost no SC soils were found in the study area as it is not characteristic of fluvial sediments to contain such mixtures. It is believed that a few samples that are classified as SC might have even been due to errors incurred during sampling as it is unlikely that sands would have been mixed with clays in a fluvial region such as Adapazarı.

Figure $3 \mathrm{c}$ depicts the distribution of the soils at the top $1.0-5.0 \mathrm{~m}$ depth in Adapazarı. One can see from here the predominance of high plasticity clays on the alluvial plain surrounding the elevated outcrops of the flysch bedrock of the Upper Cretaceous in the southeast part of the city. The districts of Tigcilar and Yenigun exhibit concentration of silty strata, mostly non-plastic, that created serious foundation problems during the 1999 earthquake. The distribution of the soils throughout the city and their geomorphology has been described in a previous publication (Bol, 2003).

\subsection{Cone tip resistance maps $\left(q_{c}\right)$}

The cone penetration test (CPT) found little use for soil investigations in Turkey until recently. This appears to have rapidly changed during the past few years as its superiority due to low cost, speed as well as yielding the complete soil profile attracted attention. Accordingly, the use of average $q_{\mathrm{c}}$ values was preferred over the borehole and SPT data in establishing the NN models within the top $5 \mathrm{~m}$ depths. Although the number of boreholes (SPT) exceeds by far that of the cone penetration test(CPT) sites used in establishing the Adapazarı geotechnical database, the averages of the $\mathrm{q}_{\mathrm{c}}$ values within the 1.0-5.0 m depths have been employed in the $\mathrm{NN}$ modelling in order to present an uninterrupted profile of the soil parameters. The CPT data are supplied for every $2 \mathrm{~cm}$ penetrated, whereas sampling is usually done at $150 \mathrm{~cm}$ intervals in the standard penetration test. The soil layers at 0.0 to $1.0 \mathrm{~m}$ have not been taken into consideration, because they are mostly above the ground water table and had undergone repeated wetting-drying cycles and also because the footing depths exceeded it. One can observe from Fig. 1 that the number and the distribution of the sounding locations in forming the thematic maps are quite satisfactory. The tip resistances $q_{\mathrm{c}}$ used for the purpose are the recorded values, and neither correction nor normalization has been performed on those (Fig. 3d). The blue zones indicate sites where $q_{\mathrm{c}}$ values were below $1 \mathrm{MPa}$, turquoise $2 \mathrm{MPa}$, the yellow zones $4 \mathrm{MPa}$, while the red regions depict sites that indicated $q_{\mathrm{c}}>8 \mathrm{MPa}$.

\subsection{Physical soil properties maps}

Since it is necessary to supply the soil properties to establish the NN model, the thematic maps for average grain size (Fig. 3e), fines content (Fig. 3f), liquid limit (Fig. 3g), plasticity index (Fig. 3h) and liquidity index (Fig. 3i) were prepared in the GIS medium in order to relate local soil conditions to damage. The distribution of the colours indicates a surprising similarity between the fines contents and the liquid limits in those maps. Zones of clay concentrations provide higher tip resistances than those of silts and sands. The predominance 
Table 3. Soil categories used in the soil map.

\begin{tabular}{ll|ll|ll}
\hline $\begin{array}{l}\text { Soil } \\
\text { Category }\end{array}$ & TS1500/2000 & $\begin{array}{l}\text { Soil } \\
\text { Category }\end{array}$ & TS1500/2000 & $\begin{array}{l}\text { Soil } \\
\text { Category }\end{array}$ & TS1500/2000 \\
\hline 1 & CH and MH & 4 & CL & 7 & SW-SM and SP-SM \\
2 & CI & 5 & ML & 8 & SP and SW \\
3 & MI & 6 & SM & 9 & G (Gravels) \\
\hline
\end{tabular}

of non-plastic profiles in the plasticity maps for the heavily damaged districts of Tigcilar and Yenigun is obvious.

\section{Soil cross sections}

Since the soil type and the values of plasticity index $I_{\mathrm{P}}$, liquid limit $w_{\mathrm{L}}$, liquidity index $I_{\mathrm{L}}$, average grain size $D_{50}$, fines content FC, cone tip resistance $q_{\mathrm{c}}$ and the liquefaction potential index LPI were used as input in the NN modelling and the damage distribution map was used as output with different units and magnitudes, a normalization operation was performed using the following equation:

$X=\frac{\left(x_{i}-x_{\min }\right)}{\left(x_{\max }-x_{\min }\right)}$.

Here $x_{i}$ indicates the quantity to be normalized, whereas $x_{\max }$ and $x_{\min }$ show the maximum and the minimum values of all the data, respectively. The maximum and the minimum values recorded in the developed maps are given in Table 4. It is possible to derive profiles along an axis and to obtain the digital values using the GIS-based software MapInfo. Two soil cross sections A and B along profiles shown in Fig. 2 have been established on the normalized maps described above. Ten profiles of $1400 \mathrm{~m}$ lengths, each containing 140 data emerged, providing the investigator with information every $10 \mathrm{~m}$ are depicted in Figs. 5 and 6 . The value of a variable has been listed with the corresponding damage ratio. The A1, A2, A3 cross sections of group $\mathrm{A}$ have been employed for training and the cross section $\mathrm{A}-\mathrm{A}^{\prime}$ as test data. The same approach has been used for group $B$ where cross sections B1, B2, B3, B4 and B5 were used for training and cross section $\mathrm{B}-\mathrm{B}^{\prime}$ as test data.

\section{Selecting the input and output parameters: sensitivity analysis}

The dynamic, physical and the mechanical properties of the soils and the resulting cross sections were employed in the input layer. Similarly, the profiles obtained from the damage ratio map were used as target layer in the process of modelling using the NN. It is clear that utmost care should be given to the choice of the input parameters in order to be able to make use of the NN architecture efficiently. This necessitates avoiding the use of parameters of little significance
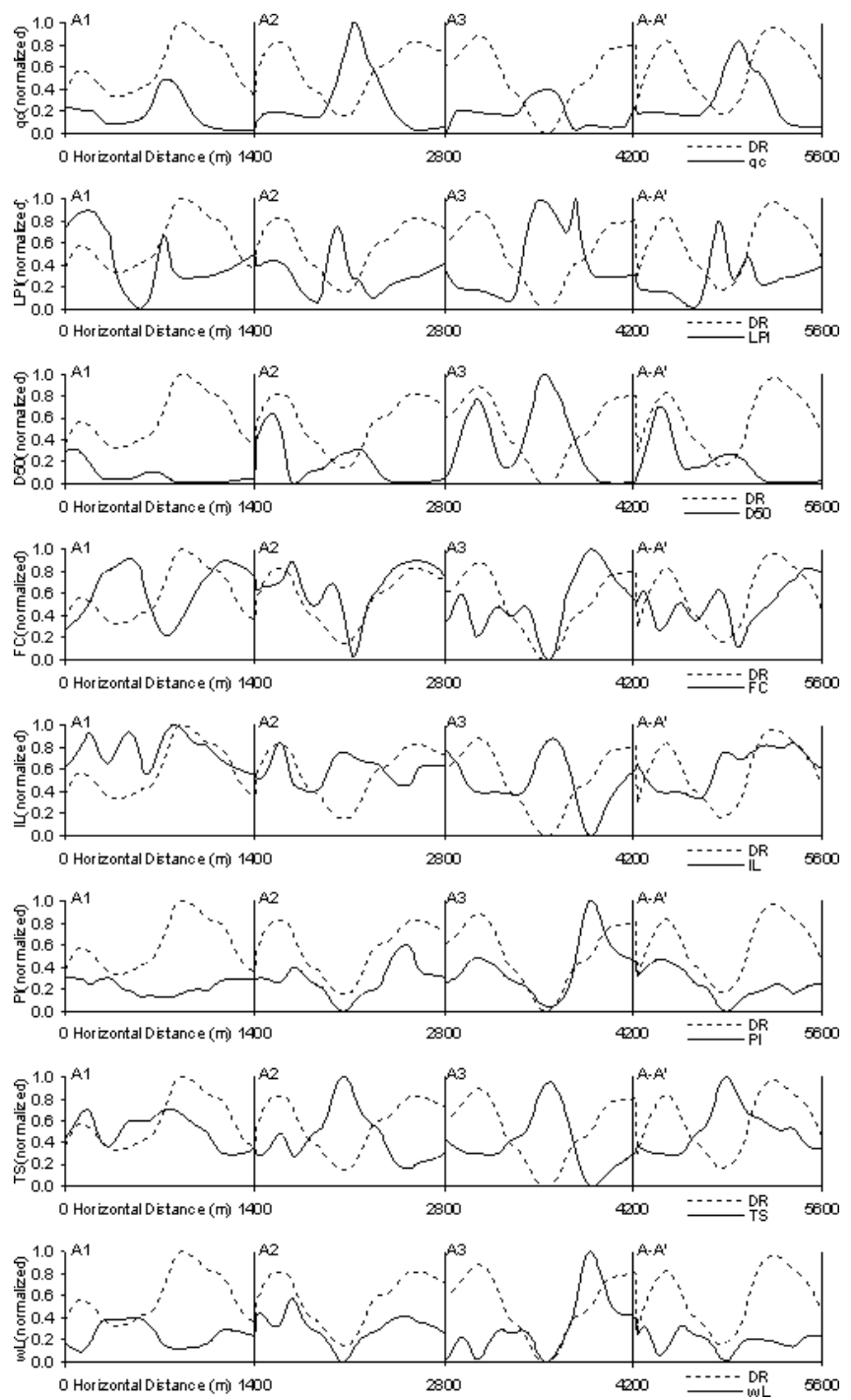

Fig. 5. Group A cross sections.

and those repetitive ones that usually lead to the same result. The network, whose architecture is depicted in Fig. 7, was used for the purpose. The model comprises four layers and the first input layer has two variables. The LPI values, which reflect the seismic performance of the soils, have been kept constant, whereas the second layer (consisting of the variables $\left.w_{\mathrm{L}}, q_{\mathrm{c}}, \mathrm{FC}, D_{50}, I_{\mathrm{L}}, I_{\mathrm{P}}\right)$ and the class of soil TS have been separately introduced into each model while evaluating 
Table 4. The maximum and the minimum values in the thematic maps.

\begin{tabular}{rrrrrrrrrr}
\hline & $\mathrm{DR}$ & $\mathrm{LPI}$ & $q_{\mathrm{c}}(\mathrm{MPa})$ & $D_{50}(\mathrm{~mm})$ & $\mathrm{FC}(\%)$ & $I_{\mathrm{L}}$ & $w_{\mathrm{L}}(\%)$ & $I_{\mathrm{P}}(\%)$ & $\mathrm{TS}$ \\
\hline$x_{\min }$ & 0.00 & 0.026 & 0.432 & 0.001 & 1.048 & 0.062 & $\mathrm{NP}$ & $\mathrm{NP}$ & 1 \\
$x_{\max }$ & 0.587 & 31.66 & 15.515 & 1.275 & 100 & 2.655 & 55.984 & 84.937 & 9 \\
\hline
\end{tabular}
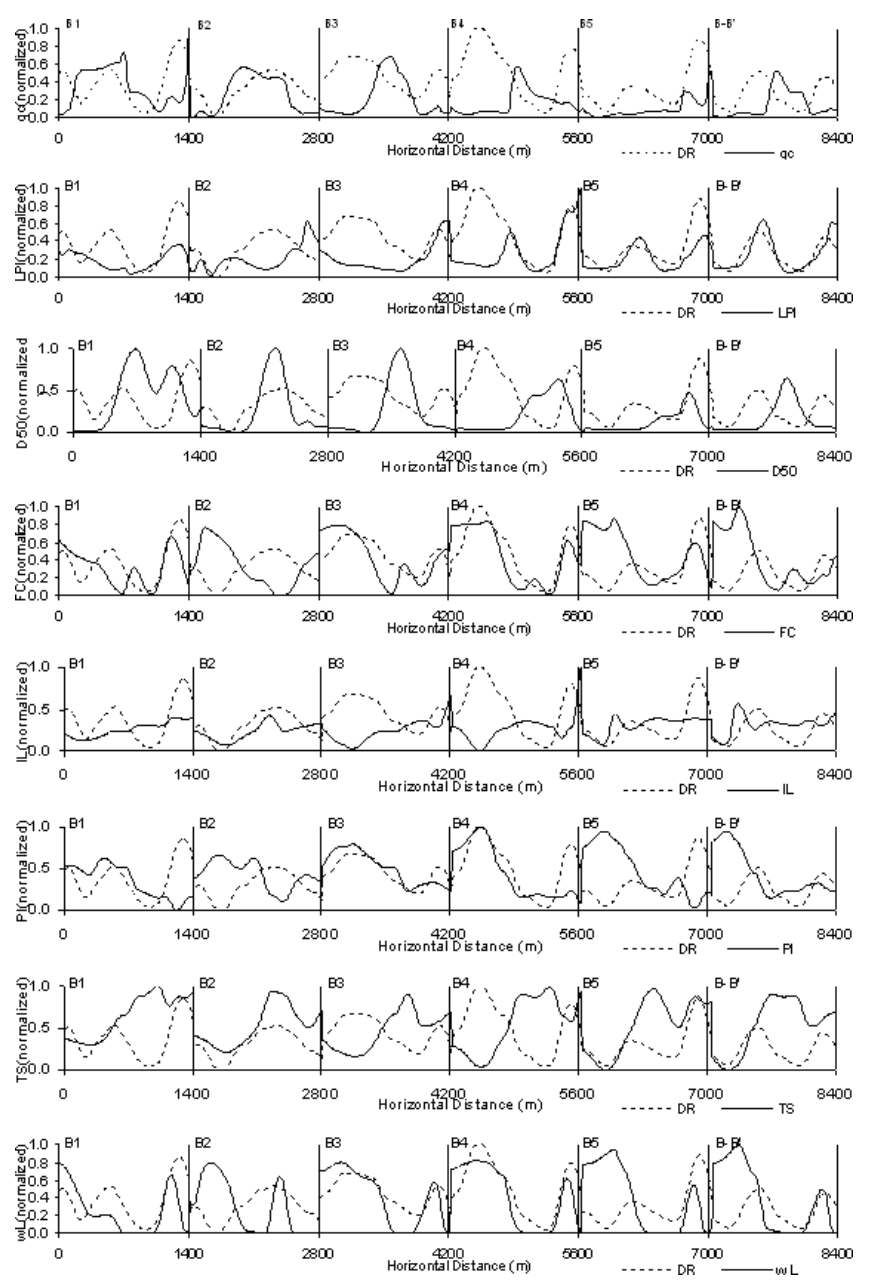

Fig. 6. Group B cross sections.

their influence. The hidden layers representing the second and the third layer have 5 and 2 neurons, respectively. The output layer is the damage ratio (DR) that has a single neuron. Figure 7 in addition shows the modelling results trained by each variable. Those results were tested against the data in the cross section $\mathrm{A}-\mathrm{A}^{\prime}$ and their similarity compared. At this stage it was observed that the input layer formed by the use of the liquidity indices has a correlation coefficient $\left(R^{2}\right)$ as low as 0.1817 , which is clearly unacceptable. In contrast, it was found that the cone tip resistance and the average grain size contributed significantly to the solution. The model thus constructed yielded similar results for the tests of the NN models. This is confirmed by the finding that the colour zones in

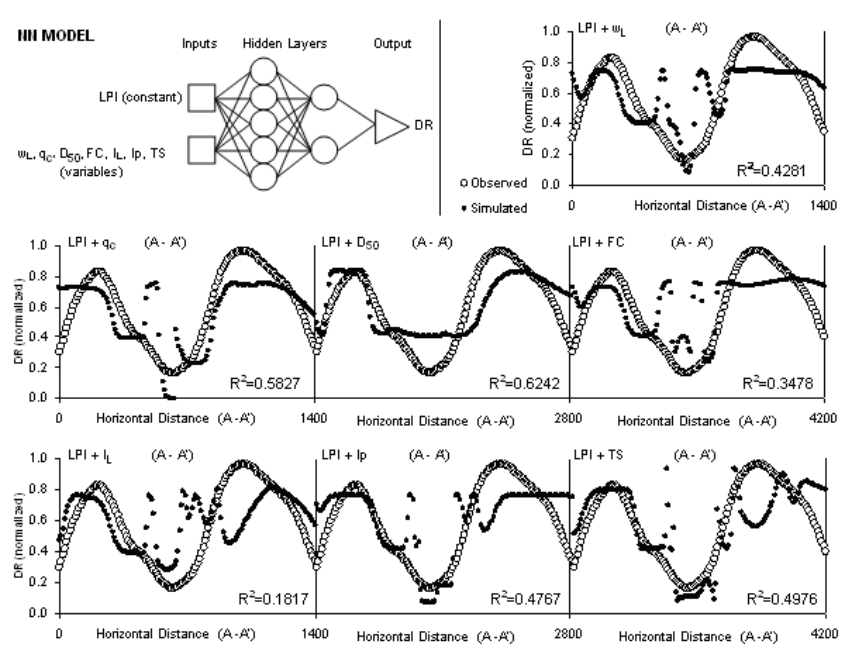

Fig. 7. The NN model used to select the effective parameters and the influence of each parameter in the solution of the problem.

the maps of Fig. 3 were almost identical for FC and $w_{\mathrm{L}}$. It was consequently decided to exclude the variables FC and $I_{\mathrm{L}}$ from the models to avoid repetition.

\section{Choice of a suitable NN model}

One of the typical shortcomings encountered in forming neural networks is overfitting. This causes memorization rather than learning with the result that the model is incapable of generalization, thus failing to produce correct results. This undesirable trend can be diagnosed by the excessive errors in the test data compared to those of training phase. The issue of deciding on the numbers of layers and the number of neurons for the optimum network structure is important. The most suitable numbers of layers and the neurons in them to arrive at the optimum epoch can best be attained by trial and error. The Group A cross sections have been selected to evaluate the performance of the formed networks. The models have been trained using the results of $\mathrm{A} 1, \mathrm{~A} 2$ and $\mathrm{A} 3$ cross sections as input (LPI, $q_{\mathrm{c}}, D_{50}, w_{\mathrm{L}}, I_{\mathrm{P}}$, class (TS)) and output (DR), and each model has been tested against the results of cross section $\mathrm{A}-\mathrm{A}^{\prime}$. This way, the input parameters obtained from $\mathrm{A}-\mathrm{A}^{\prime}$ at test stage have been imported into the established model and it was expected to estimate the damage ratio (DR) for the same section.

A study of the literature has shown that, for most problems, one or two hidden layer architecture is adopted. 
Table 5. Estimation of optimum network structure.

\begin{tabular}{rrrrrrrrrrrrrrrrrrr}
\hline \multicolumn{110}{c}{ Neurons in the first hidden layer } \\
\hline Epochs & 1 & 2 & 3 & 4 & 5 & 6 & 7 & 8 & 9 & 10 & 11 & 12 & 13 & 14 & 15 \\
\hline 100 & 0.412 & 0.420 & 0.700 & 0.537 & 0.381 & 0.334 & 0.524 & 0.807 & 0.623 & 0.593 & 0.874 & 0.772 & 0.600 & 0.758 & 0.843 \\
250 & 0.410 & 0.420 & 0.844 & 0.626 & 0.809 & 0.658 & 0.829 & 0.804 & 0.861 & 0.855 & 0.882 & 0.864 & 0.874 & 0.878 & 0.854 \\
500 & 0.394 & 0.420 & 0.811 & 0.639 & 0.879 & 0.831 & 0.754 & 0.795 & 0.878 & 0.826 & 0.878 & 0.863 & 0.837 & 0.873 & 0.811 \\
750 & 0.409 & 0.420 & 0.818 & 0.631 & 0.847 & 0.832 & 0.761 & 0.795 & 0.875 & 0.811 & 0.876 & 0.841 & 0.788 & 0.815 & 0.809 \\
1000 & 0.403 & 0.421 & 0.815 & 0.765 & 0.856 & 0.746 & 0.884 & 0.809 & 0.846 & 0.879 & $\mathbf{0 . 8 9 0}$ & 0.849 & 0.760 & 0.774 & 0.741 \\
1500 & 0.387 & 0.419 & 0.806 & 0.656 & 0.839 & 0.800 & 0.755 & 0.792 & 0.850 & 0.792 & 0.880 & 0.859 & 0.727 & 0.731 & 0.746 \\
2000 & 0.385 & 0.419 & 0.804 & 0.673 & 0.831 & 0.799 & 0.773 & 0.790 & 0.833 & 0.761 & 0.875 & 0.865 & 0.708 & 0.709 & 0.738 \\
3000 & 0.351 & 0.419 & 0.799 & 0.884 & 0.832 & 0.887 & 0.789 & 0.770 & 0.835 & 0.698 & 0.859 & 0.869 & 0.690 & 0.684 & 0.718 \\
4000 & 0.345 & 0.419 & 0.796 & 0.878 & 0.824 & 0.882 & 0.787 & 0.744 & 0.855 & 0.683 & 0.841 & 0.872 & 0.695 & 0.673 & 0.690 \\
\hline Avg. & 0.388 & 0.420 & 0.799 & 0.699 & 0.789 & 0.752 & 0.762 & 0.790 & 0.829 & 0.767 & $\mathbf{0 . 8 7 3}$ & 0.850 & 0.742 & 0.766 & 0.772 \\
\hline
\end{tabular}

* The biggest coefficient of determination value of models.

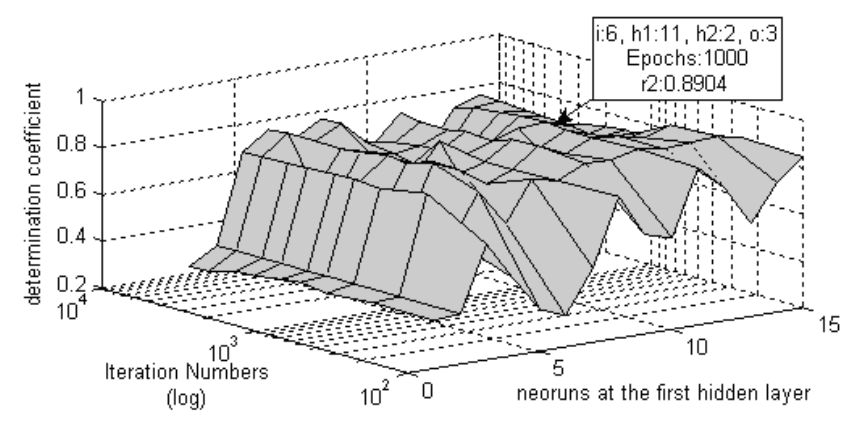

Fig. 8. 3-D surface of determination coefficients.

Training has initially been done with a single layer which is appointed with different neuron numbers to be followed by two-layer applications. The single-layer approach has not been successful. Better results have been obtained in models with two hidden layers if the second layer consisted of two neurons. Further detailed analyses were implemented to discover the optimum number of neurons for the case of a single hidden layer. Table 5 shows the number of neurons for each of the 15 models thus constructed. The number of iterations to yield the best result was investigated to avoid over-training and the distribution of the coefficient of determination $\left(R^{2}\right)$ to determine the performance of the network. All the results are presented in Table 5. Figure 8 shows a three-dimensional description of the coefficients of determination produced by the iteration numbers resulting from changes of the coefficients of determination in the first hidden layer. The study has shown that the best performance $\left(R^{2}=0.8904\right)$ is attained by the model that has 11 neurons in the first and 2 neurons in the second layer when the model was trained by 1000 iterations. The architecture of the model developed is shown in Fig. 9.

The estimates of the damage ratio arrived at by using the A group on cross section $\mathrm{A}-\mathrm{A}^{\prime}$ by $\mathrm{NN}$ model are shown in Fig. 10. One can see from this figure that there is notable agreement between the observed distribution of damage

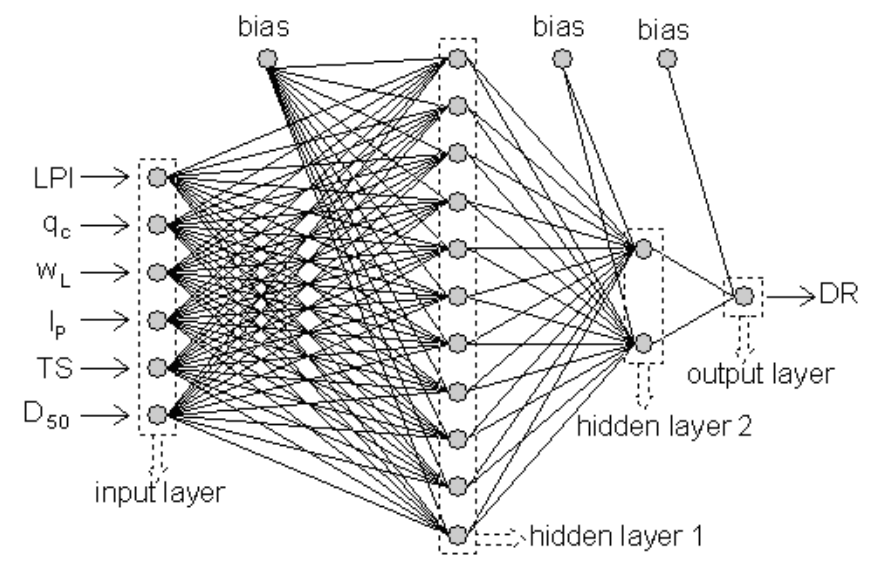

Fig. 9. The architecture of the NN model.
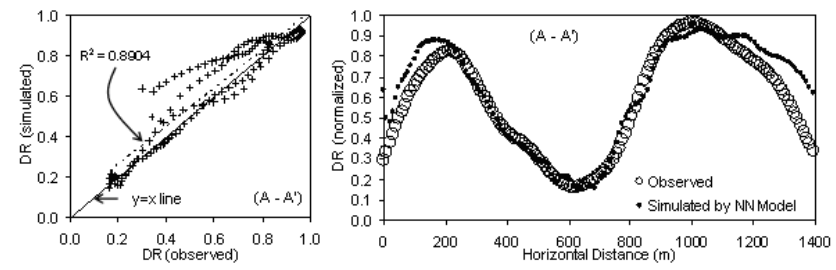

Fig. 10. The observed and simulated damage ratios for cross section $\mathrm{A}-\mathrm{A}^{\prime}$.

recorded in GIS medium along cross section $\mathrm{A}-\mathrm{A}^{\prime}$ and the simulated results arrived by the use of NN. The NN model proposed for Group A has also been used for the training of Group B. The proposed model has been trained with the cross sections B1, B2, B3, B4 and B5 and an attempt to simulate along the cross section $\mathrm{B}-\mathrm{B}^{\prime}$. The results observed and

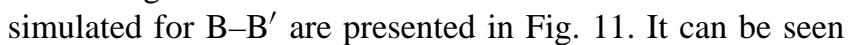
from here that, although full agreement was not achieved $\left(R^{2}=0.6309\right)$, the damage distribution simulated by the NN has a striking similarity to the observed values. It is clear that 

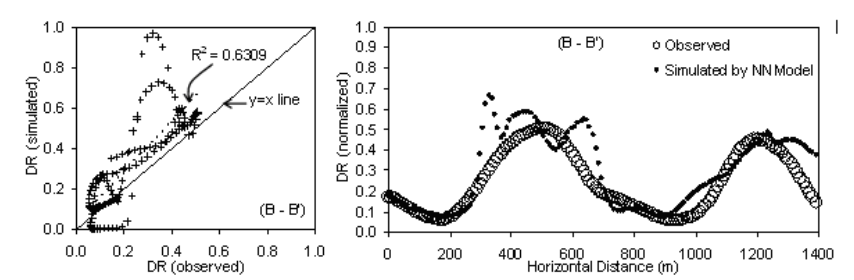

Fig. 11. The observed and simulated damage ratios for cross section $\mathrm{B}-\mathrm{B}^{\prime}$.

a major part of the error involved in cross section $\mathrm{B}-\mathrm{B}^{\prime}$ is due to the fact that the buildings here are more "heterogeneous" from geometric, structural and even architectural aspects. It is also noteworthy that these buildings may have been designed in conformity with any of three superseding building codes. The B- $\mathrm{B}^{\prime}$ cross section trained in the A-Group has also been tested. The NN model trained with the cross sections $\mathrm{A} 1, \mathrm{~A} 2$ and $\mathrm{A} 3$ has been tested to estimate the damage in cross section B-B ${ }^{\prime}$ and the result is given in Fig. 12. A general agreement is obvious, but the extent of damage has been over or underestimated due to probable uncertainties concerning the quality of construction.

\section{Conclusions}

The buildings in the districts constituting the southeast side of Adapazarı are founded on bedrock. Accordingly, the damage recorded during the 1999 Marmara earthquake in these zones was recorded to be negligible despite the fact that the quality of construction is the same as others in the city. Heavy damage and destruction was observed in districts where the thickness of alluvium went as deep as $1000 \mathrm{~m}$. The majority of the researchers on the topic are convinced that the inflicted damage can be attributed to the poor soil conditions. Ground failures in the form of liquefaction, cyclic softening and bearing capacity have been observed after the earthquake. Indeed, the extent of damage in the districts of Tigcilar and Yenigun shows that the damage had been augmented where cases of liquefaction were frequent. Inferior soil conditions have also contributed to tilting, toppling and excessive settling of the buildings. Although such events rendered many buildings to become uninhabitable, they nevertheless seem to have prevented catastrophic structural failures such as pancaking, because the soil acted as a form of base isolator.

It was observed that the distribution of the damage was not homogeneous throughout the city where collapses were frequent in some districts and minimal in others. The explanation for this difference is believed to be the relative rigidity of different types of thick soil layers. The soft soil zones acted as natural base isolators, whereas it is believed that stiff clay layers overlying the deep and sand-gravel strata forming the ancient riverbeds might have readily transferred the effect of the earthquake to the superstructure, resulting in damage.

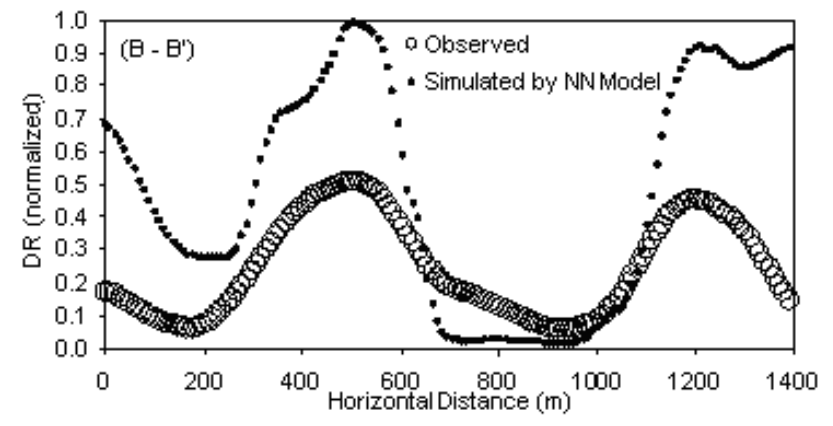

Fig. 12. The observed and simulated damage ratios for cross section $\mathrm{B}-\mathrm{B}^{\prime}$ (NN trained by Group A sections).

In this paper, the relationship between the physical, mechanical, dynamic properties of the soils and the general distribution of earthquake damage has been evaluated on the NN platform. The established model was found to estimate damage with surprising accuracy in districts with homogeneous building stock. The uncertainties emanating from designs, under ever-changing building codes of Turkey and questionable construction quality, prevented the investigator from deriving an error-free model. This suggests that damage was inflicted not only by inferior soil conditions but also poor construction practices.

In any case, it is clear that the structural features of the buildings cannot possibly be incorporated into this type of study, because a detailed inventory of the collapsed and surviving buildings in the study area would have been necessary. It is believed nevertheless that the results of this study can be applied in similar areas of fluvial origin in the future and necessary precautions can then be recommended to avoid extensive damage. One can confidently warn the authorities concerned about the zones of possible damage leading to disaster dimensions in the future with the help of such a study presented here.

Acknowledgements. A major part of this study has been performed through the support of TUBITAK (104M042), the Turkish Foundation for Scientific and Technical research. Their contribution is gratefully acknowledged.

Edited by: M. E. Contadakis

Reviewed by: E. Dogan and one anonymous referee 


\section{References}

Bakir, B. S., Sucuoglu, H., and Yilmaz, T.: An overview of local site effects and the associated building damage during the $17 \mathrm{Au}-$ gust 1999 İzmit earthquake, B. Seismol. Soc. Am., 92, 509-526, 2002.

Bakır, S., Yılmaz, M. T., Yakut, A., and Gülkan, P.: Re-examination of damage distribution in Adapazar1: Geotechnical considerations, Eng. Struct., 27, 1002-1013, 2005.

Bol, E.: The Geotechnical Properties of Adapazari Soils, PhD Thesis, Sakarya University, Adapazari, Turkey, 195 pp., 2003 (in Turkish).

Bol, E., Özocak, A., and Arel, E.: Liquefaction of silty soils and liquefaction map of Adapazari city, in: Proceedings of the International Conference Earthquake Engineering in 21st Century, University St. Cyril and Methodius, IZIIS, Skopje/Ohrid, Republic of Macedonia, 2005.

Bol, E., Önalp, A., and Özocak, A.: The Liquefiability of silts and the vulnerability map of Adapazari, in: Proceedings of the 14th World Conference on Earthquake Engineering, Beijing, China, 12-17 October, Paper no. 1071, 2008.

Bray, J. D., Sancio, R. B., Durgunoglu, T., Onalp, A., Youd, T. L., Stewart, J. P., Seed, R. B., Çetin, Ö. K., Bol, E., Baturay, M. B., Christensen, C., and Karadayilar, T.: Subsurface characterization at ground failure sites in Adapazari, Turkey, J. Geotech. Geoenviron. Eng., 130, 673-685, 2004a.

Bray, J. D., Sancio, R. B., Riemer, M. F., and Durgunoglu, T.: Liquefaction susceptibility of fine-grained soils, in: Proceedings of the 11th International Conference on Soil Dynamics and Earthquake Engineering and 3rd International Conference on Earthquake Geotechnical Engineering, University of California, Berkeley, CA, 7-9 January, 655-662, 2004b.

Bray, J. D., Sancio, R. B., Youd, L. F., Christensen, C., Cetin, O., Onalp, A., Durgunoglu, T., Stewart, J. P. C., Seed, R. B., Baturay, M. B., Karadayilar, T., and Emrem, C.: Documenting incidents of ground failure resulting from the August 17, 1999 Kocaeli, Turkey Earthquake, Pacific Earthquake Engineering Research Center, available at: http://peer.berkeley.edu/publications/ turkey/adapazari/index.html/ last access: 28 June 2012.

İnce, G. Ç.: The relationship between the performance of soil conditions and damage following an earthquake: a case study in Istanbul, Turkey, Nat. Hazards Earth Syst. Sci., 11, 1745-1758, doi:10.5194/nhess-11-1745-2011, 2011.
Iwasaki, T., Tatsuoka, F., Tokida, K. I., and Yasuda, S.: A practical method for assessing soil liquefaction potential based on case studies at various sites in Japan, in: Proceedings of the second international conference on microzonation, San Francisco, 885896, 1978.

Komazawa, M., Morikawa, H., Nakamura, K., Akamatsu, J., Nishimura, K., Sawada, S., Erken, A., and Önalp, A.: Bedrock structure in Adapazari, Turkey-a possible cause of severe damage by the 1999 Kocaeli earthquake, Soil Dynam. Earthq. Eng., 22, 829-836, 2002.

Kramer, S.: Geotechnical earthquake engineering, Upper Saddle River, NJ, Prentice-Hall, 1996.

Lettis, W., Bachhuber, J., Witter, R., Brankman, C., Randolph, C. E., Barka, A., Page, W. D., and Kaya, A.: Influence of Releasing Step-Overs on Surface Fault Rupture and Fault Segmentation: Examples from the 17 August 1999 Izmit Earthquake on the North Anatolian Fault, Turkey, B. Seismol. Soc. Am., 92, 19-42, 2002.

MacMurdo, J.: Papers relating to the earthquake which occurred in India in 1819, Philosophical Magazine, 63, 105-177, 1824.

Moller, A. F.: A scaled conjugate gradient algorithm for fast supervised learning, Neural Networks, 6, 525-533, 1993.

Önalp, A., Arel, E., and Bol, E.: A General assessment of the effects of 1999 earthquake on the soil-structure interaction in Adapazarı, Jubilee Papers in Honour of Prof. Dr. Ergün Toğrol, XV ICSMFE, Istanbul, Turkey, 76-89, 2001.

Robertson, P. K. and Wride, C. E.: Evaluating cyclic liquefaction potential using the cone penetration test, Can. Geotech. J., 35, 442-459, 1998.

Sancio, R. B., Bray, J. D., Stewart, J. P., Youd, T. L., Durgunoglu, H. T., Önalp, A., Seed, R. B., Christensen, C., Baturay, M. B., and Karadayilar, T.: Correlation between ground failure and soil conditions in Adapazari, Turkey, Soil Dynam. Earthq. Eng., 22, 1093-1102, 2002.

Trifunac, M. D. and Todorovska, M. I.: Nonlinear soil response as a natural passive isolation mechanism: 1994 Northridge, California earthquake, Soil Dynam. Earthq. Eng., 17, 41-51, 1998.

Turkish Institute of Standardization, TS-1500: Classification of soils for civil engineering purposes, TSE, Ankara, Turkey, 2000 (in Turkish). 